\title{
UM APORTE AO SISTEMA CONTÁBIL GERENCIAL AMBIENTAL: SEGUNDA GERAÇÃO DE INDICADORES
}

\author{
João Paulo de Oliveira Nunes \\ Mestre em Contabilidade pela Universidade Federal de Santa Catarina - UFSC \\ Professor da Universidade Federal de Santa Catarina - UFSC \\ jpfloripa@yahoo.com.br \\ Elisete Dahmer Pfitscher \\ Doutora em Engenharia de Produção pela Universidade Federal de Santa Catarina - UFSC \\ Professora da Universidade Federal de Santa Catarina - UFSC \\ elisete@cse.ufsc.br \\ Vivian Osmari Uhlmann \\ Mestre em Contabilidade da Universidade Federal de Santa Catarina - UFSC \\ vouhlmann@gmail.com
}

\section{RESUMO}

Esta pesquisa tem como objetivo geral analisar o Sistema Contábil Gerencial Ambiental (Sicogea), propondo melhorias ao sistema. Este estudo enquadra-se metodologicamente como descritivo, com análise de dados qualitativa. Já, sua trajetória metodológica consistiu em, primeiramente, realizar uma fundamentação teórica acerca do tema abordado, e, em seguida, fez-se uma análise das convergências e divergências das aplicações do Sicogea, e da estrutura do método, apresentando a estrutura metodológica do Sicogea - Geração 2, com outras formas de indicadores e nova estrutura da lista de verificação. Como resultado, obteve-se a proposta metodológica do Sicogea - Geração 2, com as três etapas, suas fases e ações a serem realizadas na sua aplicação no sentido de uma gestão dos fatores ambientais, sendo os principais resultados: alteração na estrutura da lista de verificação buscando uma padronização entre os ramos de atividades ou mesmo diferenciados; assim, dividiu-se a lista por grupos-chave e subgrupos, utilizando a mesma denominação de grupos-chave para todas as aplicações; inclusão de questões-chave nos itens da lista; atribuição de pontos diferentes por questão a critério do analista, variando de acordo com a relevância do atendimento ao meio ambiente; inclusão da planilha de ponderação para facilitar o agrupamento e cálculo da sustentabilidade geral e parcial; outra estrutura de indicadores; e inclusão de duas fórmulas para identificar os índices de eficiência dos itens.

Palavras-chave: Contabilidade ambiental; Indicadores ambientais; Sicogea; Sustentabilidade; Sicogea Geração 2.

\section{A CONTRIBUTION TO ENVIRONMENTAL MANAGEMENT ACCOUNTING SYSTEM: SECOND GENERATION INDICATORS}

\section{ABSTRACT}

This research aims at analyzing the SICOGEA (Environmental Management Accounting System) and proposing improvements to the system. The study conducted was descriptive methodological and methodological with qualitative analysis. The methodology consisted of first performing a theoretical foundation about the subject matter according to an analysis of convergence and divergence of applications SICOGEA and structure analysis method; showing the structure of methodological SICOGEA - Generation 2 with other form indicators and new structure of the checklist. As a result we obtained the proposed methodology SICOGEA - Generation 2, with three steps, stages and actions to be taken in its application towards the management of environmental factors. The results indicate a change in the structure of the list seeking verification standardization between the branches of activities or differences; so we divided the list into groups and sub-key using the same designation of key groups for all applications, including key issues in the list items. The form consisted of answers from 0 (zero) to 5 (five), allowing a variation in the care of questioning conducted with a weighting of $0 \%$ to $100 \%$, awarding points for different questions varying according to the relevance of care in the environment, including consideration of the spreadsheet to facilitate the collation and calculation of the overall sustainability and partial structure of other indicators, including two formulas to identify the efficiency indices of the items, and suggestion of the $5 \mathrm{~W} 2 \mathrm{H}$ framework for future applications.

Keywords: Sustainability; Environmental accounting; SICOGEA; SICOGEA - Generation 2; Environmental indicators. 


\section{INTRODUÇÃO}

Com o passar do tempo, a população mundial está evoluindo na ideia de preservação dos recursos naturais existentes na Terra, para a sobrevivência das gerações futuras. Para tanto, buscam formas de utilização mais consciente dos recursos e novas alternativas de matrizes energéticas, com menor impacto ao meio ambiente. Neste sentido, desenvolver métodos que venham a auxiliar na gestão ambiental e seguir de maneira mais ambientalmente sustentável se faz necessário.

Conforme Hart e Milstein (2004), é necessário para uma empresa, que busca ser sustentável, gerar benefícios econômicos alinhados a interesses sociais e ambientais. Os mesmos autores salientam que o alinhamento entre interesses econômicos e preservacionistas constitui o pilar básico do desenvolvimento sustentável.

Quando se pensa em gestão ambiental, em termos de recursos consumidos pela empresa em sua cadeia de valor, na fabricação de seus produtos ou prestação de seus serviços, muitas vezes, necessita-se conciliar recursos financeiros com atitudes de responsabilidade socioambiental. Estas medidas de gestão ambiental vêm trazer para a administração das empresas uma responsabilidade na gestão dos recursos, para que a entidade possa gerar resultados positivos, tanto financeiramente quanto um produto de qualidade, sem que tenha gerado impactos negativos ao meio ambiente ao longo do processo produtivo.

Para Van Bellen (2002, p.16), gestão ambiental diz respeito ao “[...]desenvolvimento e aplicação de sistemas de indicadores ou ferramentas de avaliação que procuram mensurar a sustentabilidade". Assim sendo, uma das maneiras encontradas para verificar o quanto uma entidade interfere no meio ambiente é por meio do cálculo de sustentabilidade, seja em um ente econômico, governamental, com ou sem fins lucrativos.

Desta forma, surgiram sistemas de gestão ambiental, com base nas premissas das normas ambientais e agregando ferramentas de gestão às suas metodologias, para buscar melhores formas de obter dados e gerar informações aos usuários. Este foi o caso do método denominado Sistema Contábil Gerencial Ambiental - Sicogea, que teve sua origem em outro método, denominado Gestão dos Aspectos e Impactos Ambientais - GAIA ambos alinhados à norma ISO 14001.

Tendo como base estas considerações, tem-se a seguinte pergunta de pesquisa: quais pontos podem ser fortalecidos na estrutura metodológica do Sistema Contábil Gerencial Ambiental Sicogea?

Este questionamento propiciou que se fixasse o seguinte objetivo de pesquisa: propor um aporte ao Sistema Contábil Gerencial Ambiental - Sicogea.

O estudo referente ao meio ambiente ainda tem muito a ser explorado e a evoluir, no sentido de buscar tratamentos mais eficazes e procedimentos que resultem em menos impactos, com uma maior economia. Nesse sentido, esta pesquisa visa contribuir, com sua fundamentação teórica, para os debates em pauta na atualidade.

A implementação de um sistema de gestão ambiental pode proporcionar ao gestor uma visão de como a organização interage com o meio ambiente e, ainda, buscar formas de melhorar esta relação. Para tanto, o sistema utilizado deve ser constituído de uma metodologia que minimize quaisquer dúvidas quanto aos seus resultados e formas de aplicação.

Cabe ressaltar que essa pesquisa desenvolveu um aporte ao método Sicogea, sem desconsiderar a existência de outros métodos relacionados ao gerenciamento ambiental. No entanto, os resultados alcançados pelo estudo dizem respeito apenas a este método específico de avaliação da sustentabilidade e desempenho ambiental.

\section{FUNDAMENTAÇÃO TEÓRICA}

Estrutura-se, neste capítulo, a base teórica necessária para a análise dos resultados, por meio de uma revisão de literatura, trazendo definições de contabilidade ambiental, gestão ambiental e 
sistemas de gestão ambiental. Além disso, aborda-se o método que deu origem ao aporte proposto nesta pesquisa, o Sicogea.

\subsection{Contabilidade ambiental}

A contabilidade ambiental é um ramo da contabilidade, que possui objetivos específicos, tais como identificar e mensurar eventos e transações econômico-financeiros que estejam relacionados com a proteção, preservação e recuperação ambiental, visando à evidenciação da situação patrimonial da organização no momento em que ocorreram (Ribeiro, 2005,).

A sociedade pode utilizar a contabilidade ambiental em prol do meio ambiente e do próprio proveito, por meio das ações das entidades, selecionando aquelas com tratamentos ambientais mais adequados (Marion e Costa, 2007).

Ao se preocupar em auxiliar no processo de gestão dos recursos naturais, a contabilidade tem também como objetivo registrar os eventos internos da entidade, que tenham relação com o meio ambiente, considerando os aspectos e efeitos que possam vir a ocorrer, ou seja, os impactos de uma gestão inadequada destes recursos.

Neste sentido, a contabilidade pode auxiliar os mais variados usuários, gerando relatórios com informações úteis às empresas ou mesmo à sociedade, no que diz respeito ao gerenciamento do meio ambiente e à mensuração das atividades relacionadas aos eventos ambientais (Paiva, 2003).

\subsection{Gestão ambiental}

Conforme Oliveira, Perez Junior e Silva (2004), grande parte da destruição sofrida pela natureza ocorreu em decorrência do capitalismo industrial, o que vem ocorrendo em volume considerável ainda hoje. Não se atendo para as consequências destas atitudes, em tempo hábil, o ser humano passou a buscar o uso maior de recursos renováveis e menos poluentes, minimizando os impactos negativos no meio ambiente. Este cenário precisa ser repensado pelas empresas e sociedade como um todo.

Neste sentido, o mesmo autor define gestão do meio ambiente, como sendo diretrizes e atividades, tanto administrativas quanto operacionais, envolvendo fatores como planejamento, direção controle, sempre procurando gerar efeitos positivos no meio ambiente, protegendo-o das ações humanas.

Para Tachizawa (2004), quando a empresa busca ser competitiva, com um maior desenvolvimento de seus negócios, a gestão ambiental pode ser um instrumento importante para esta busca, pois possibilita que a organização tenha um diferencial perante a concorrência, por vincular o nome dessa entidade a uma grande influência do fator ecológico em sua gestão.

O processo de gestão do meio ambiente, para Barbieri (2006) e Ávila e Paiva (2006), definise como sendo diretrizes e atividades, administrativas e operacionais, utilizando processos, tais como planejamento, direção e controle, buscando um aprimoramento da relação das atividades da organização, com os fatores ambientais. Assim, os autores sustentam que para tornar possível esta gestão, devem-se estruturar Sistemas de Gestão Ambiental (SGA), que é uma estrutura que segue padrões, de forma sistematizada e que possibilita gerar informações, para gerenciar as atividades referentes ao meio ambiente.

\subsection{Sistemas de gestão ambiental}

Em busca de uma conservação da biodiversidade, considerando o fator ecológico, seja qual for o ramo de atividade, as empresas devem seguir alguma forma de saber os impactos de suas ações sobre o meio ambiente. Neste sentido, Turner (2009) defende que, na busca de reduzir possíveis degradações ao meio, o desempenho ambiental das empresas devem ser observados, e para isso, a aplicação de um sistema de gestão ambiental, se mostra como uma ferramenta útil neste processo de gestão ao meio ambiente, podendo proporcionar uma melhoria contínua da situação ao longo do tempo. 
Quanto a sua implementação, Cerqueira e Martins (2004), sugerem que estes sistemas devem atender primeiramente a padrões pré-definidos, e devem, posteriormente, ser constantemente monitorados, para verificar se ainda está atingindo os objetivos iniciais propostos para sua aplicação, de acordo com os rumos traçados pela organização.

Para Andrews et al. (2001), os sistemas de gestão ambiental se constituem de uma estrutura formal que seguem políticas e procedimentos adequados às organizações que dela utilizam, para gerir possíveis impactos sobre o ambiente e a saúde das pessoas. Para isso, as empresas utilizam modelos como ISO 14001, que fornece um modelo para aplicação, que permite realizar auditorias e gerar certificações por terceiros, quanto à conformidade das normas ali existentes.

A norma auxilia as entidades que busquem uma melhor relação com os fatores ambientais, ou mesmo um reconhecimento por seus esforços, na proteção ao meio ambiente, uma certificação validada por terceiros, conforme atendimento a padrões pré-estabelecidos, de acordo com a política ambiental, objetivos e metas estimados pela organização.

\subsection{Sistema contábil gerencial ambiental - Sicogea}

O Sicogea é uma ferramenta de gestão ambiental, que une contabilidade, por meio de controles, ao meio ambiente. O objetivo deste sistema é gerar informações ao gestor sobre os impactos das suas ações no meio ambiente, com o auxílio da contabilidade e controladoria ambiental, e teve sua origem no Gerenciamento dos Aspectos e Impactos Ambientais (Ávila, 2001), que, por sua vez, não é relatado na base teórica, apenas por informação.

De acordo com Pfitscher (2004), o Sicogea possui três etapas distintas: integração da cadeia; gestão de controle ecológico e; gestão da contabilidade e controladoria ambiental, que consiste na avaliação da relação dos setores da entidade com o meio ambiente, em que se verificam suas ações e influências no processo de decisão. Esta terceira etapa possui três fases: a primeira "Investigação e Mensuração", que apresenta a "Sustentabilidade e estratégia ambiental", "Comprometimento" e a "Sensibilização das partes interessadas"; a segunda fase é a "Informação", que vai mapear a cadeia de produção. E, por fim, a "Decisão", em que se identificam as oportunidade de melhoria e suas viabilidades por meio de planejamento. A metodologia do Sicogea é descrita nos itens a seguir.

\section{a) Integração da cadeia produtiva}

Esta fase busca ter uma visão sistêmica do processo de produção, desde o início até o final da cadeia, identificando necessidades de vários setores na empresa, e verifica possíveis danos ao meio ambiente causados por cada atividade. Além disso, busca-se a formação do grupo que irá atuar no processo, verificando o quanto estão comprometidos com as questões ambientais e a melhoria dos procedimentos que possam estar causando algum dano ambiental.

Assim, se confirmado o interesse, passa-se para a próxima etapa, em caso contrário, deve-se realizar a ação de convencimento, visando despertar o interesse dos envolvidos na participação do processo de melhoria ambiental, caso o interesse ainda não se confirme, deverá ser finalizada a operação.

Após, realizada as Fases 1 e 2, "Formação dos grupos de trabalho" e "Discussão das matrizes de identificação e Exame dos efeitos ambientais", respectivamente, conforme Nome de Pfitscher (2004), estas etapas podem conter palestras e workshops, para expor para os envolvidos a sua forma de atuação sobre o meio ambiente, com a preparação de uma planilha de gerenciamento de aspectos e impactos ambientais. E ainda, desenvolver uma forma de discussão acerca de métodos de produção mais limpas, ou seja, mais sustentáveis.

\section{b) Gestão do controle ecológico}

Passada a primeira etapa, busca-se identificar os setores na empresa, que possam estar causando impactos ambientais na produção, para, em seguida, reduzi-los ou eliminá-los, por meio de implementação de uma gestão ecológica. Faz-se o levantamento do setor que a entidade está 
inserida, e realiza-se um diagnóstico da organização, em alinhamento com outras atividades do sistema produtivo, buscando ainda, formas de agregar valor ao produto, reaproveitando resíduos ou formas que não utilizem resíduos que possam causar poluição (Nunes et al., 2009).

Passada a fase de diagnóstico e levantamento da situação de seu sistema de produção, partese para a próxima fase, a "Gestão de contabilidade e controladoria ambiental", lembrando que todas estas fases deverão alimentar o banco de dados da análise da entidade.

Vale ressaltar que no estudo realizado por Pfitscher (2004), se utilizou os termos "Agropolo Biodinâmico", "Propriedades Rurais" e entre outras expressões, isso se deve, por ter sido aplicado em uma Cadeia Produtiva de Arroz, contudo, deve haver alterações quando aplicado em outro tipo de empresa.

Esta etapa busca verificar a realidade da atuação da empresa sob o meio ambiente, realizando estudos para compor o diagnóstico e descrevendo o sistema de produção e interação com outras atividades.

\section{c) Gestão da contabilidade e controladoria ambiental}

Passadas as etapas de convencimento dos atores participantes do processo, do diagnóstico da situação com o levantamento dos aspectos e impactos ambientais, surge à intenção de investigar os fatores financeiros e econômicos, em alinhamento com as características operacionais da organização, com isso, geram-se informações aos gestores e propostas de melhoria para contribuir com o meio ambiente (Nunes et al., 2009).

A terceira etapa está estruturada em 3 (três) fases, sendo a primeira "Investigação e Mensuração", a segunda fase é "Informação" e, por fim, a terceira fase "Decisão". Tendo em vista que, os processos operacionais e gestão da empresa já foram abordados, surge à iniciativa de verificar os efeitos ambientais nos fatores financeiros e econômicos da entidade analisada.

Nesta etapa, que se aplica a lista de verificação, um questionário que busca saber dos gestores e responsáveis pela organização pesquisada sobre sua atuação em relação ao meio ambiente, calculando o grau de sustentabilidade global e parcial e, por meio disso, saber o seu desempenho ambiental.

Ao identificar os pontos a serem melhorados, após o mapeamento da cadeia produtiva e levantamento do inventário de aspectos e impactos ambientais, o analista verifica as formas de atuação e estrutura um planejamento a ser conduzido junto aos gestores. Estas fases são identificadas e descritas, em seus procedimentos de aplicação, nos itens a seguir.

\subsubsection{Fase 1: Investigação e mensuração}

Esta fase está subdividida em 3 (três) ações centrais, em que busca-se saber a sustentabilidade e estratégia ambiental por meio do desempenho ambiental e contábil, ao ser aplicada uma lista da verificação, estruturada em critérios e subcritérios; como segunda ação está a busca do comprometimento em alinhamento com a terceira ação, sensibilização das partes interessadas.

As ações que constam na estrutura da Primeira Fase - Terceira Etapa do Sicogea busca, inicialmente, identificar o desempenho ambiental da entidade com o auxílio da contabilidade ambiental, isso se faz por meio de uma lista de verificação, estruturada em critérios e subcritérios.

Em seguida, busca-se o comprometimento dos agentes envolvidos, sensibilizando-os, quanto à questão ambiental, para atendimento das propostas de melhoria que são apresentadas em outra fase. Apresenta-se, de forma detalhada, cada ação desta fase, nos itens a seguir.

\subsubsection{Ação 1 - Sustentabilidade e estratégia ambiental}

Para a ação 1, em busca do nível de sustentabilidade, é verificada por meio de uma lista de verificação, dividida em critérios e subcritérios, aplicado na forma de uma entrevista semiestruturada ou questionário, aos responsáveis pela entidade qual melhor informação poderá se 
ter acerca da gestão ambiental, e suas respostas são quantificadas com a aplicação de um conceito, que pode ser "Adequada" ou "Deficitária", que desta forma, utiliza-se uma fórmula de cálculo de sustentabilidade, que demonstra seu desempenho ambiental, estando inserido, neste momento, o desempenho contábil, que possibilita ao analista ter uma visão financeira, econômica e gerencial dos fatores ambientais, com o levantamento de ativos e passivos ambientais, e "[...]análise do balanço ambiental patrimonial[...]", que possibilita complementar as informações obtidas (Nunes et al. 2009, p. 179).

Sendo assim, o grau de sustentabilidade é obtido, por meio das respostas da "lista de Verificação", que são atribuídas às seguintes letras pelo pesquisador: "A" - ADEQUADA; "D" DEFICITÁRIA; e "NA" - NÃO SE ADAPTA À EMPRESA. A partir disso, são aplicadas na seguinte fórmula: Grau de Sustentabilidade é igual ao número de Questões "A" multiplicado por 100, sendo este valor dividido pelo número total de questões diminuídas das questões "NA".

Após serem calculados os índices, os critérios e subcritérios, compara-se o resultado de sustentabilidade obtida, a um grau de avaliação de desempenho ambiental, conforme Figura 1, em que pode ser reconhecido o resultado global, ou seja, da lista completa, ou mesmo, parcial, segregando por critério e subcritérios, que possibilita uma análise geral e em partes.

\begin{tabular}{|l|l|l|}
\hline \multicolumn{1}{|c|}{ Resultado } & \multicolumn{1}{c|}{ Sustentabilidade } & \multicolumn{1}{c|}{ Desempenho: controle, incentivo, estratégia } \\
\hline Inferior a 50\% & Deficitária - "D" & Fraco, pode estar causando danos ao meio ambiente. \\
\hline Entre 51\% e 70\% & Regular - "R" & Médio, atende somente a legislação. \\
\hline Mais de 71\% & Adequado - "A" & $\begin{array}{l}\text { Alto, valorização ambiental com produção ecológica } \\
\text { e prevenção da poluição. }\end{array}$ \\
\hline
\end{tabular}

Figura 1: Avaliação da sustentabilidade e desempenho ambiental.

Fonte: Adaptado de Leripio (2001) e Miranda e Silva (2002).

Assim, a gestão ambiental, com a utilização da contabilidade e controladoria ambiental, que gera informações que poderão contribuir para os que gestores realizem uma melhor decisão, em se tratando de diminuir impactos sobre o meio, possibilita, ainda, que a instituição demonstre seus esforços sobre a atuação neste setor, uma mensuração de valores incorridos neste processo.

\subsubsection{Ação 2 - Comprometimento}

Para esta ação, são levantados a Missão, a Visão, a Política e os Objetivos da organização, buscando verificar a existência de fatores ambientais atendidos nestes elementos de cultura e em sua gestão, e possibilitando ocorrer alguma alteração nestes itens, assim como, e ainda, visa dar sequência a próxima ação, que é a sensibilização das partes interessadas acerca do tema (Nunes et al. 2009).

\subsubsection{Ação 3 - Sensibilização das partes interessadas}

Conforme Pfitscher (2004), nesta ação é importante realizar visitas a entidade e realizar minicursos, acerca dos resultados alcançados, em que se busca identificar os atores envolvidos na gestão (colaboradores, fornecedores, comunidade, órgãos ambientais, entre outros), e sensibilizá-los para aplicação das propostas sugeridas, onde deverá ocorrer o acompanhamento dos participantes e o agrupamento de responsabilidades.

\subsubsection{Fase 2: Informação}

Nesta fase, conforme Nunes et al. (2009), o analista busca extrair, da fase anterior, as informações obtidas com a aplicação da lista de verificação e análise do balanço patrimonial ambiental, para compartilhá-las com os demais interessados, como é o caso do estudo de entradas e saídas dos processos, inventário de aspectos e impactos ambientais (Pode ser classificada em escala de valores: crítica; moderada ou desprezível) e mapeamento da cadeia de produção, levantando 
assim, o ciclo de vida do produto na empresa, as matérias-prima utilizadas, e ainda, identificando custos na produção. Deste modo, busca-se identificar formas de melhor utilizar os fatores de produção, gerando um menor nível de poluição e reaproveitando resíduos resultantes da produção.

De posse destas informações, o analista pode disponibilizar para os gestores e demais interessados envolvidos, qual será a próxima fase de atuação, além de fazer com que estas informações sejam aplicadas no dia a dia, beneficiando os pontos considerados de maior prioridade.

\subsubsection{Fase 3: Decisão}

De acordo com Pfitscher (2004), esta fase dá continuidade nas atuações da empresa perante o mercado, aplicando as sugestões fornecidas pelo método para as situações consideradas com maior prioridade, buscando oportunidades de melhorias, com a viabilidade técnica, contábil envolvida em um planejamento das ações ambientais, e ainda, um estudo da disponibilidade de capital a ser utilizado, para melhorias nesta área.

Conforme a mesma autora, o plano resumido de gestão ambiental é constante do planejamento desenvolvido pelo analista após as demais fases aplicadas, para isso, pode ser utilizado o método denominado 5W2H (What? Why? When?Where? Who?How e How much? - o que? Por quê? Onde? Quando? Quem? Como? Quanto Custa?), que é concebido para servir como uma ferramenta de qualidade, base utilizada pelo GAIA, e para estruturar suas sugestões de melhorias, indicando responsáveis, formas de atuações, prazos e locais a serem introduzidas as contribuições, conforme ordem de prioridade encontrada ao longo do estudo.

\section{METODOLOGIA DE PESQUISA}

A metodologia adotada para realização deste trabalho utiliza-se de técnicas e métodos científicos na obtenção de resultados relevantes ao assunto abordado. Assim, esse estudo, quanto aos objetivos, é descritivo e metodológico, pois utilizou como base a estrutura metodológica de um sistema já existente, e com isso, propôs sua alteração.

A pesquisa descritiva, de acordo com Beuren et al. (2006, p. 81), busca, segundo o objeto de estudo, identificar suas variáveis, relatar e comparar, sem ter um aprofundamento maior, como formulações de hipóteses.

Quanto à abordagem do problema, utiliza-se uma análise qualitativa, para Soares (2003, p. 19), "[...]o pesquisador interpreta os fatos, procurando soluções para o problema proposto." Esta análise é feita para interpretação de dados e busca refletir os resultados dos objetivos a serem atingidos, pois os dados coletados e analisados ao longo da pesquisa têm caráter qualitativo, mesmo que utilize algumas ferramentas quantitativas no seu percurso.

Como base para as alterações propostas, utilizaram-se três fontes secundárias principais, sendo elas: Pfitscher (2004), pesquisa em que é descrita a metodologia do Sicogea; Nunes et al. (2009), estudo realizado com o uso da estrutura do Sicogea, em que se analisam e verificam os pontos a serem alterados no método; e Vargas (2009), pesquisa que abordou convergências e divergências, com base nas várias aplicações, utilizando o sistema, e que, desta forma, resultou na estruturação do Sicogea - Geração 2.

Com base na pesquisa realizada por Vargas (2009), que fez um estudo de campo nas pesquisas aplicadas, utilizando o método Sicogea - Sistema Contábil Gerencial Ambiental, buscouse verificar as convergências e divergências no Sicogea.

Outra fonte secundária utilizada foi a pesquisa de Nunes et al. (2009), que serviu de base para discussão e análise em um evento: XI Congresso Internacional de Costos y Gestión y XXXII Congresso Argentino de Professores Universitários de Costos, que foi realizado na Argentina, no ano de 2009, surgindo alguns apontamentos que deram base para este estudo. 


\section{SISTEMA CONTÁBIL GERENCIAL AMBIENTAL (SICOGEA) - GERAÇÃO 2}

Com base nos estudos, formularam-se propostas de alterações para todas as etapas do método, com ênfase na terceira etapa, denominada "Gestão da Contabilidade e Controladoria Ambiental".

O Sicogea - Geração 2 (Sistema Contábil Gerencial Ambiental - Geração 2) é uma ferramenta de gestão ambiental, que une contabilidade, por meio de controles, com fatores ambientais, econômicos e sociais, e com isso, geram informações aos gestores, que auxiliam a melhorar a atuação das atividades das entidades sob o meio ambiente.

Inicialmente, realizou-se a alteração das nomenclaturas utilizadas no fluxo estrutural do Sicogea, pois, em decorrência de sua primeira aplicação ter sido em uma cadeia produtiva de arroz ecológico, encontra-se com sua estrutura toda voltada para esta atividade, buscando com isso, a generalização, com o intuito de facilitar o entendimento para os futuros pesquisadores que utilizarão este sistema de gestão ambiental.

O Sicogea veio para complementar o Gaia, buscando identificar fatores financeiros e econômicos que o Gaia não compreendia. Quanto a este quesito, o Sicogea - Geração 2 manteve os demais itens que adotou do Gaia, no entanto, adequou-se às exigências atuais, advindas com a alteração da lei 6.404/76, nos anos de 2007 e 2009, entre outras alterações metodológicas. Sendo assim, descreve-se a estrutura do denominado Sicogea - Geração 2.

\section{a) Integração da cadeia de valor}

Ao verificar a estrutura desta primeira etapa, deparou-se com a nomenclatura existente e sua abrangência quanto à aplicação, utilizando "cadeia produtiva". Neste contexto, entende-se que para abordar temas relacionados à sustentabilidade necessita-se não se limitar apenas a produção, mas analisar os fatores que a antecedem e a sucedem. Por ter que fazer uma análise mais abrangente, optou-se, então, por denominar esta etapa de "Integração da cadeia de valor", por agregar mais entendimento e atividades, que a nomenclatura anterior.

Com isso, o analista ao realizar esta etapa, identifica as atividades realizadas na entidade e, expõe aos agentes envolvidos no processo a importância de aplicar uma produção ecológica, que pode trazer benefícios à sociedade e a própria empresa. Desta forma, caso os gestores reconheçam e aprovem a melhoria destes fatores ambientais, passa-se para a próxima etapa. Caso não haja resposta positiva, realiza-se uma ação de convencimento, em que se busca trazer essa consciência quanto à atuação ambiental.

Nestas fases iniciais, caracterizada pela busca de convencer os gestores e formar os grupos de trabalhos, configuram-se pontos-chave para a continuidade da aplicação do método em questão, pois o comprometimento dos agentes envolvidos deve ser exposto desde o início, para não comprometer o resultado final do estudo e a disponibilidade dos dados ao analista.

\section{b) Gestão do controle ecológico}

Para a segunda etapa, o objetivo desta fase é identificar a região de atuação da entidade, para complementar o estudo da cadeia de valor. Neste contexto, busca-se descobrir a realidade, em que se encontra inserida, pelas características de mercado, as facilidades e dificuldades de obter suprimentos, fornecedores, clientes, entre outros aspectos.

Outro ponto que se optou por modificar foi quanto à fase seguinte, de "diagnóstico das propriedades rurais" para "diagnósticos das filiais ou unidades", pelo motivo semelhante ao anterior, por se tratar de uma especificidade da primeira aplicação. Por isso, buscou-se generalizar a nomenclatura desta fase. Vale ressaltar, neste aspecto, que, esta fase trata-se de uma avaliação de uma cadeia de produção, quando houver necessidade do caso, por eventualidade do ramo de aplicação. 
$\mathrm{Na}$ fase denominada "Sistema de produção e Integração com outras atividades", busca-se complementar o estudo da cadeia de valor, em que o pesquisador, com base no sistema de produção desempenhado pela organização, realiza uma análise destes processos em alinhamento a outros fatores internos e externos à empresa, anterior e posterior ao sistema de produtivo propriamente dito.

Estas três fases que compõem a segunda etapa buscam complementar o propósito de integração da cadeia de valor, destinado a revelar a estrutura de atuação da empresa e a análise conjunta de outras empresas ou enquadramento de mercado, para servir de base na análise geral e proporcionar a possibilidade de propostas de melhoria, uma vez que se sabe a respeito da realidade na qual a empresa se encontra.

\section{c) Gestão da contabilidade e controladoria ambiental}

Da mesma forma que o método anterior, esta etapa tem o objetivo de verificar fatores financeiros e econômicos aliados aos fatores ambientais inseridos nas peculiaridades operacionais de cada empresa, buscando uma valorização ambiental.

Esta etapa consiste em, primeiramente, levantar, por meio da metodologia, o grau de sustentabilidade e desempenho ambiental, que pode variar de 0 a $100 \%$, isso é possível, pois ocorre a aplicação da lista de verificação, composta por grupos-chave e subgrupos. Em conjunto é realizada a análise do Balanço Ambiental Patrimonial e a DVA e, em paralelo, realizam-se as fases de comprometimento e sensibilização das partes interessadas.

Desta forma, ocorre em seguida à fase da "Decisão", que consiste propor ações de melhorias dos pontos considerados críticos, que possam gerar algum tipo de poluição ou impacto ao meio ambiente. Assim, apresentam-se nos itens a seguir, as fases constantes nesta etapa.

\subsection{Fase 1: Investigação e mensuração}

Da mesma forma que o método anterior, este possui três ações, mas a metodologia sofreu algumas alterações, principalmente na ação 1, denominada "Sustentabilidade e estratégia ambiental", onde ocorreu modificação na estrutura da lista de verificação, no grau de sustentabilidade e desempenho ambiental, na forma de análise de indicadores, indicando com certa padronização, a maneira de identificar as prioridades a serem melhoradas.

A estrutura da primeira fase desta etapa manteve-se, a exceção destas alterações citadas, está subdividida em 3 (três) ações centrais, em que, inicialmente, busca-se identificar a sustentabilidade e estratégia ambiental, com a verificação do desempenho ambiental e contábil. Para isso, é aplicada uma lista da verificação, estruturada em Grupos-chave e subgrupos. A segunda ação, objetiva realizar o comprometimento dos agentes envolvidos no processo, em alinhamento com a terceira ação, sensibilização das pastes interessadas.

A próxima ação está vinculada com as pessoas envolvidas no processo, buscando sensibilizá-las quanto às melhorias de suas atuações em relação ao meio ambiente, e identificando as possíveis formas de conduzir esse processo. Com isso, aliando esta ação à anterior, surge a possibilidade de agrupar as responsabilidades dos agentes envolvidos para atendimento das propostas de melhoria que são apresentadas em outra fase. Apresenta-se, de forma detalhada, cada ação desta fase, nos itens a seguir.

\subsection{Ação 1 - Sustentabilidade e estratégia ambiental}

Esta Ação 1 tem como objetivo identificar a forma de atuação da entidade sob o meio ambiente. Verificou-se com as pessoas envolvidas sua percepção quanto aos mecanismos utilizados, ações ambientais, enquadramento a legislação, entre outros fatores. Isso se faz por meio de uma lista de verificação, dividida em grupos-chave e subgrupos, constantes em vários questionamentos acerca destes fatores, que pode se aplicada em forma de entrevista semiestruturada ou questionário. 
Houve também o aumento do número de categorias no quadro de avaliação de sustentabilidade, para evidenciar, de forma mais precisa, o grau de sustentabilidade que a entidade pesquisada se enquadra. Sugeriu-se o aumento para 5 (cinco) níveis, como demonstra a Tabela 1.

Tabela 1: Avaliação da sustentabilidade e do desempenho ambiental.

\begin{tabular}{l|l|l}
\hline \multicolumn{1}{c|}{ Resultado } & Sustentabilidade & \multicolumn{1}{c}{ Desempenho: controle, incentivo, estratégia } \\
\hline Inferior a 20\% & Péssimo - "P" & Pode estar causando grande impacto no meio ambiente. \\
\hline Entre 21 a 40\% & Fraco - "F" & $\begin{array}{l}\text { Pode estar causando danos, mas surgem algumas poucas } \\
\text { iniciativas. }\end{array}$ \\
\hline $\begin{array}{l}\text { Entre 41\% e } \\
60 \%\end{array}$ & Regular - "R" & Atende somente a legislação. \\
\hline $\begin{array}{l}\text { Entre 61\% a } \\
80 \%\end{array}$ & Bom - "B" & $\begin{array}{l}\text { Além da legislação, surgem alguns projetos e atitudes que } \\
\text { buscam valorizar o meio ambiente. }\end{array}$ \\
\hline Superior a 80\% & Ótimo - "O" & $\begin{array}{l}\text { Alta valorização ambiental com produção ecológica e } \\
\text { prevenção da poluição. }\end{array}$ \\
\hline
\end{tabular}

Fonte: Adaptado de Leripio (2001) e Pfitscher (2004).

Buscou-se segregar em mais faixas de desempenho, para quantificar a análise com maior detalhamento, pois anteriormente, resultados que obtinham percentuais com diferença considerável, poderiam ter seus desempenhos igualados em uma mesma categoria, em razão disso, ponderou-se então, uma diferença de $20 \%$ para cada categoria. Assim, apresenta-se nos próximos itens, a estrutura da lista de verificação.

\section{a) Estrutura da lista de verificação}

Buscou-se formar uma nova estrutura para a lista de verificação com o objetivo de convencionar os grupos-chave e subgrupos, na intenção de comparabilidade de análises entre estudos da mesma área, para isso, utilizou-se o estudo realizado por Nunes et. al. (2009), que alinhou a análise com cálculos estatísticos convencionais, nova estrutura de indicadores e estrutura da lista de verificação. Em seguida, é apresentada a nova forma de estrutura e suas análises.

Estas nomenclaturas são utilizadas na organização da análise do estudo, sendo posteriormente relacionadas com outras formas de denominação, como o caso de grupo-chave, ser apresentado como "Processo"; subgrupo ser indicado como "subprocesso"; e na lista de verificação sendo denominados de "Grupo" e "Critério", respectivamente.

\section{- Grupos-chave}

$\mathrm{Na}$ busca de um formato padrão para reunir fatores de análises em diferentes estudos, adotase uma estrutura básica de mercado, compreendendo quatro níveis de abordagem, denominados Grupos-chave.

Primeiramente, abordam-se os itens relacionados com a "Produção", subdivididos em itens que demonstrem, em base sustentáveis, o sistema operacional da entidade, desde seus fornecedores, passando pela linha de produção até chegar a distribuição final de seus produtos ou serviços. Outro item abordado é denominado de Marketing, que busca evidenciar as formas de ação utilizadas pela empresa na atuação ambiental e a divulgação destes itens, não apenas para atender a legislação, mas também, como um diferencial de mercado.

O terceiro fator pesquisado está alinhado ao capital humano, item denominado "Recursos humanos", que visa saber o nível de treinamento e a formação das pessoas atuantes em todos os processos da empresa e, ainda, os indivíduos que atuam diretamente na área ambiental. 
Por fim, o quarto quesito é denominado "Financeiro", porém pode abordar não somente fatores financeiros, mas também, econômicos e contábeis. Desta forma, cada grupo-chave, passa a ser dividido em subgrupos de questões, anteriormente denominados subcritérios.

\section{- Subgrupos}

Assim como destacado no Capítulo 4, os subgrupos constituem fatores existentes na área pesquisada, podendo variar conforme a realidade de cada entidade, e funcionam de forma a subdividir os grupos-chave, como, por exemplo, na "Produção": processo de produção; fornecedores; manutenção, entre outros.

\section{- Questões-chave}

Considerou-se necessário algum questionamento que realize, de forma geral, uma comprovação dos itens individuais perguntados, visando reconhecer as formas de controle destes fatores, por parte da empresa. Dessa forma, buscou-se em cada subgrupo, realizar uma questão, denominada Questão-chave, de maneira mais profunda e direta, com ferramentas utilizadas de forma sistematizada na gestão do meio ambiente, e no acompanhamento destes processos, para melhoria contínua.

Ao utilizar esta estrutura, permitiu a possibilidade de o respondente atribuir avaliação parcial quanto ao questionamento, que parte de 0 (zero) chegando ao máximo em 5 (cinco) pontos, o que possibilitou demonstrar em que nível a empresa se enquadra, como se apresenta no Figura 02, exemplo da estrutura proposta.

\begin{tabular}{|c|c|c|c|c|c|c|c|c|}
\hline & ÁREA 3 - MARKETING & \multicolumn{7}{|c|}{$\begin{array}{l}\text { De } 0 \text { a } 5 \text { minha } \\
\text { empresa é: }\end{array}$} \\
\hline & $\begin{array}{c}\text { Subgrupo 01 - RESPONSABILIDADE } \\
\text { SOCIOAMBIENTAL }\end{array}$ & $\mathbf{0}$ & 1 & 2 & 3 & 4 & 5 & $\mathbf{N A}$ \\
\hline 94 & $\begin{array}{l}\text { A empresa identifica os aspectos e trata os impactos sociais e } \\
\text { ambientais de seus produtos, processos e instalações sobre os } \\
\text { quais tenha influência? ( } 2 \text { pontos) }\end{array}$ & & & & & & & \\
\hline
\end{tabular}

Figura 2: Modelo de questionário e atribuição de pontos por tema pesquisado.

Fonte: Adaptado de Nunes et. al. (2009).

O estudo realizado por Nunes et. al. (2009), considerou a seguinte escala para atribuição de valor de atendimento por parte da entidade, na visão do entrevistado .

Como se pode perceber, a estrutura da lista de verificação possibilita ao analista atribuir pontos para cada questão, de maneira a ser considerada no cálculo dos indicadores na sequência da análise do caso. Esta pontuação ponderada para cada questão, não é divulgada ao respondente, para não resultar em distorção das respostas.

A alternativa "NA - não se aplica" deve ser considerada, pois poderá ocorrer algum questionamento que, em razão da especificidade do objeto de estudo, não se enquadre, assim, possibilita ao analista descartar tal questionamento, não prejudicando as demais análises e o cálculo de sustentabilidade, mas isso somente ocorrerá em exceções.

\section{b) Planilha de ponderação}

Seguindo a sugestão de Nunes et. al. (2009), a utilização de uma planilha de ponderação visa agrupar, de forma organizada, os dados, com as respostas aos questionamentos, dadas pelo entrevistado.

Em complemento a planilha de ponderação e a estrutura da lista de verificação realizam-se alguns esclarecimentos em relação à obtenção dos escores, que resultam nos índices analisados. 
Entre os elementos a serem verificados, estão à obtenção do escore para cada questão, os pontos possíveis atribuídos pelo analista e o cálculo dos grupos-chave e subgrupos.

\section{- Obtenção do escore para cada questão}

Com a possibilidade de o entrevistado atribuir resposta parcial para cada questionamento, de (0) zero - não satisfaz - a (5) cinco - que atende plenamente a questão, em cada nível de resposta corresponde a um percentual crescente - partindo de $0 \%$ até $100 \%$, em intervalos de $20 \%$ cada patamar. Como exemplo, pode-se perceber que na questão 6 , o respondente atribuiu nota 2 ao atendimento. Sendo assim, esta pergunta obteve um escore de $40 \%$ do total possível de pontos da questão, o nível obtido de pontos alcançados atingiu 0,4 pontos.

Seguindo esta análise, a ponderação deve ser realizada para todas as questões da lista de verificação. Nesse processo, deve observar o percentual de atendimento a questão, informado pelo respondente, para, em seguida, aplicar sobre o total de pontos possíveis atribuídos pelo analista.

\section{- Pontos atribuídos para as questões (pontos possíveis)}

Os pontos atribuídos são de critério do analista, e não devem ser informados ao entrevistado. Na tabela de ponderação, estes valores estão informados na coluna denominada "Pontos Possíveis", vale destacar, neste aspecto que é recomendável que pesquisador atribua peso maior para as questões julgadas de maior relevância na lista de verificação.

Como identificado no Capítulo 4 e conforme Nunes et. al. (2009), a coerência deve ser mantida na atribuição desses pesos nas diferentes questões, buscando seguir um procedimento único para toda a lista de verificação, em não ocorrendo, podem comprometer os resultados.

Utilizando os pontos possíveis e o escore obtido em cada questão, resulta na obtenção da soma de pontos alcançados em cada grupo-chave e subgrupo, o que possibilita ser comparado ao total de pontos possíveis, que, por sua vez, permitirá que se conheça o grau de sustentabilidade da empresa ou desempenho de cada grupo-chave e subgrupo.

\section{c) Cálculo da contribuição dos grupos-chave e subgrupos}

$\mathrm{Na}$ busca de uma equalização entre os grupos-chave ou subgrupos, em relação ao resultado geral, tenta-se identificar quais fatores existentes, em cada um deles e quanto contribuíram ou comprometeram o resultado final obtido. Deste modo, as fórmulas funcionam para igualar o potencial de cada grupo-chave ou subgrupo. Assim, demonstra-se a Fórmula 1 - Cálculo para formação do percentual de contribuição de cada grupo-chave, constante na Figura 3.

\begin{tabular}{|c|c|}
\hline \multirow{2}{*}{$\begin{array}{c}\text { \% contribuição do } \\
\text { grupo-chave }=\end{array}$} & $\begin{array}{c}\text { (total de pontos possíveis do grupo-chave / total de pontos } \\
\text { alcançados }) \times\left(100 / \mathrm{n}^{\mathrm{o}} \text { total de grupos-chave do questionário }\right)\end{array}$ \\
\cline { 2 - 2 } & 100 \\
\hline
\end{tabular}

Figura 3: Fórmula para o percentual de contribuição do grupo-chave.

Fonte: Nunes et. al. (2009)

Esta fórmula consiste na soma total dos pontos possíveis do grupo-chave, dividido pelo número total de pontos alcançados, multiplicados pelo fator de contribuição de cada grupo-chave, sendo que este é obtido por 100 dividido pelo número de grupos-chave da lista de verificação. Após isso, divide-se por 100, para se obter o percentual de participação no resultado, de cada grupochave.

Igualmente ao cálculo da contribuição dos grupos-chave, realiza-se o cálculo para saber a participação de cada subgrupo e, desta forma, possibilitar a identificação dos itens prioritários para atendimento na gestão ambiental. Assim, apresenta-se a Fórmula 4 - Cálculo para formação do percentual de contribuição de cada subgrupo. 


\begin{tabular}{|c|c|}
\hline \multirow{2}{*}{$\begin{array}{c}\% \text { contribuição } \\
\text { do subgrupo }=\end{array}$} & $\begin{array}{c}\text { (total de pontos possíveis do subgrupo / total de pontos } \\
\text { alcançados }) \times\left(100 / \mathrm{n}^{\mathrm{o}} \text { total de subgrupos do questionário }\right)\end{array}$ \\
\cline { 2 - 3 } & 100 \\
\hline
\end{tabular}

Figura 4: Fórmula para o percentual de contribuição do subgrupo.

Fonte: Nunes et. al. (2009).

Esta segunda fórmula consiste na busca da contribuição de cada subgrupo, em relação à lista de verificação ou a cada grupo-chave individualmente, caso o analista desejar. Para isso, utiliza-se o total de pontos possíveis para cada subgrupo, divide-se pelo total de pontos alcançados, multiplicando-os, em seguida, pelo fator de participação, que é obtido com 100 dividido pelo número total de subgrupos do questionário ou grupo-chave e, por fim, dividindo-se este número obtido por 100.

Ao verificar os percentuais obtidos em cada subgrupo, observa-se o grau de sustentabilidade e desempenho ambiental, e, com isso, surge o questionamento de quanto cada subgrupo participa no desempenho total. Para isso, utiliza-se a Fórmula 2, demonstrada na Figura 4, que evidencia esta participação.

Com o somatório do índice de eficiência por subprocesso ajustado obtém-se um percentual semelhante ao índice geral de sustentabilidade, com uma pequena variação, devido ao ajuste.

\section{d) Definição de prioridades de melhoria}

Para definir os pontos considerados prioritários, o estudo realizado por Nunes et. al. (2009), sugere seguir alguns passos específicos, na busca para se ter uma base que permita obter estas prioridades de melhoria, sendo assim, identificou estes itens:

i) Escolher os subgrupos com menor pontuação;

ii) Reportar-se ao questionário e observar as respostas cujo escore atingiu, no máximo, o escore 3 , ou seja, $60 \%$ do total de pontos possíveis;

iii) Priorizar os temas que atribuem maior importância no questionário, ou seja, nas questões onde o número de pontos possíveis é maior;

Não há necessidade de seguir esta ordem como está estruturada, ficando a critério do analista identificar os pontos mais críticos de cada estudo. Porém, em não havendo uma base sólida de definição para identificar os itens de melhoria, pode-se seguir esta lógica.

Desta forma, ao utilizar estes parâmetros, pode-se perceber que, partindo dos índices obtidos pelos grupos-chave ou subgrupos, identificam-se os de menor desempenho; em seguida, o analista pode identificar os questionamentos com menores escores; outra forma, é levar em consideração questões de com maiores pontos possíveis, e as que apresentaram baixo desempenho.

\section{e) Forma de avaliação dos indicadores}

De posse dos dados obtidos com a aplicação da lista de verificação, inicia-se o processo de análise dos indicadores, começando pelo índice geral de sustentabilidade; em seguida, é realizada a análise do índice de eficiência por processo; e, por fim, efetua-se o estudo por subprocesso, identificando assim, as prioridades de atendimento.

\section{- Índice geral de sustentabilidade da empresa}

Utilizando a planilha de ponderação, pode-se obter os dados coletados com a lista de verificação, o que, por sua vez, possibilita calcular o índice geral de sustentabilidade, que consiste em confrontar os pontos alcançados, com os possíveis. Esta mesma forma de análise pode ser realizada para cada grupo-chave ou subgrupo, verificando seus indicadores individuais. Com a apresentação da Tabela 2, pode-se identificar qual o índice obtido pela empresa. 
Tabela 2: Índice geral de sustentabilidade da empresa.

\begin{tabular}{|l|c|}
\hline \multicolumn{2}{|c|}{ Índice geral de sustentabilidade da empresa } \\
\hline Pontos possíveis & $\mathrm{X}$ \\
\hline Pontos alcançados & $\mathrm{Y}$ \\
\hline Escore & $(\mathbf{Y} / \mathbf{X}) * \mathbf{1 0 0}=\mathbf{Z \%}$ \\
\hline
\end{tabular}

Fonte: Adaptado de Nunes et. al. (2009).

$\mathrm{Na}$ Tabela 2, pode-se perceber que os pontos possíveis estão identificados pela letra ' $\mathrm{X}$ ', mostrando quantos pontos a lista de verificação possui para cada estudo. A letra ' $\mathrm{Y}$ ' representa os pontos alcançados com as respostas ponderadas somadas de cada questão. Com isso, busca-se um percentual de sustentabilidade e desempenho ambiental, a ser comparado com a tabela de avaliação do desempenho ambiental.

\section{- Índice de eficiência por processo na empresa}

O índice de eficiência tem como objetivo demonstrar qual foi o desempenho dos gruposchave, podendo-se proceder da maneira apresentada no índice anterior ou sendo seu índice ajustado. Para a estrutura da lista de verificação, optou-se por esta representação: "Produção"; "Recursos Humanos"; "Marketing"; e "Finanças e Contabilidade".

Outra forma identificada de análise, é a intenção de igualar a participação de cada grupochave no resultado geral, para isso, realiza-se o ajustamento dos índices, aplicando um fator de participação, obtido com 100 dividido pelo número de grupos analisados. Dessa forma, utilizou-se a Formula 1. Para exemplificar, adotaram-se os dados que constam em Nunes et. al. (2009), para a Tabela 3, que apresenta os índices de eficiência para os processos.

Tabela 3: Índice de eficiência por processo (grupos-chave) na empresa - ajustado.

\begin{tabular}{l|c|c|c}
\multicolumn{1}{c|}{ Processo } & Índice de eficiência & Diferença & Total \\
\hline Produção & $13,39 \%$ & $11,61 \%$ & $25 \%$ \\
\hline Recursos humanos & $15,43 \%$ & $9,57 \%$ & $25 \%$ \\
\hline Marketing & $12,60 \%$ & $12,40 \%$ & $25 \%$ \\
\hline Finanças e contabilidade & $19,84 \%$ & $5,16 \%$ & $25 \%$ \\
\hline Total & $\mathbf{6 1 , 2 6 \%}$ & $\mathbf{3 8 , 7 4 \%}$ & $\mathbf{1 0 0 \%}$ \\
\hline
\end{tabular}

Fonte: Nunes et. al. (2009).

Com a equiparação dos níveis de participação, pode-se identificar, no resultado geral, o quanto cada grupo participou, não modificado pelo número de questões ou pontos possíveis. Sendo esta uma forma de abordagem, mesmo sabendo que a participação de um grupo com poucos pontos possíveis, seja igualada a outro com uma quantidade maior de pontos possíveis, considera-se relevante esta abordagem, pois se pode identificar a participação de cada grupo no resultado geral, em forma de eficiência de desempenho.

Utilizando esses percentuais do exemplo, identifica-se que o índice de eficiência do grupochave Finanças, obteve o melhor desempenho, ficando com 19,86\% de 25\%; a coluna diferença demonstra o quanto falta para obter o nível máximo de participação. Em contrapartida, o grupochave Marketing, ficou com pior nível de participação, com $12,60 \%$ dos $25 \%$ possíveis, demonstrando uma diferença de $12,40 \%$ para o nível máximo.

Vale salientar que o procedimento de equiparação, conforme Nunes et. al. (2009), tem como objetivo realizar a composição final destes indicadores, com participação igual para todos no resultado geral, não podendo assim, haver a comparação entre o índice geral de sustentabilidade e a soma total destes indicadores de eficiências ajustados. 


\section{- Índice de eficiência por subprocesso da empresa}

Para o índice de eficiência concentrada por subprocessos, procede-se da mesma maneira que o indicador anterior, buscando a participação de cada subgrupo no resultado final, ponderando um fator de envolvimento igual para todos, obtido por meio de 100 dividido pelo número de subprocessos, identificados na lista de verificação como "Critérios". A Tabela 4 apresenta os índices de eficiência segregados por subprocesso.

Tabela 4: Índice de eficiência por subprocessos (subgrupos) na empresa - ajustado.

\begin{tabular}{|l|c|c|}
\hline \multicolumn{1}{|c|}{ Subprocesso } & Indice de eficiência & Diferença \\
\hline Processo de produção & $5,71 \%$ & $8,57 \%$ \\
\hline Fornecedores & $7,82 \%$ & $6,47 \%$ \\
\hline Manutenção & $10,29 \%$ & $4,00 \%$ \\
\hline Tratamento dado aos colaboradores & $11,26 \%$ & $3,03 \%$ \\
\hline Gestão da empresa & $7,05 \%$ & $7,23 \%$ \\
\hline Responsabilidade socioambiental & $7,20 \%$ & $7,09 \%$ \\
\hline Contab. Gerencial/ auditoria ambiental & $11,34 \%$ & $2,95 \%$ \\
\hline Total & $\mathbf{6 0 , 6 7 \%}$ & $\mathbf{3 9 , 3 3 \%}$ \\
\hline
\end{tabular}

Fonte: Nunes et. al. (2009)

Observando os dados identificados por esse exemplo, utilizada a Fórmula 2 para obter esses percentuais, pode-se notar que o índice do subprocesso Contabilidade Gerencial/Auditoria ambiental, obteve o melhor desempenho, com 11,34\% de eficiência, ficando com uma diferença de apenas 2,95\% para o máximo valor de participação. Por outro lado, o subprocesso Processo de Produção ficou com um índice de eficiência de 5,71\%, com um desempenho abaixo dos demais, como identifica a coluna "diferença", sendo este com maior percentual.

Conforme Nunes et al. (2009), este procedimento de equiparação tem como objetivo evidenciar os dados em uma forma equilibrada de participação, seja por meio de tabelas ou gráficos, proporcionando ao analista observar quais indicadores necessitam de maior atenção, em relação aos demais. Lembrando que com o ajuste realizado, sempre ocorre uma variação, se comparado ao índice geral de sustentabilidade.

Já a "Ação 2 - Comprometimento" e "Ação 3 - Sensibilização das Partes Interessadas" foram mantidos da mesma forma que relatadas no Sicogea. Bem como a "Fase 2 - Informação" e "Fase 3 - Decisão", sendo esta última acrescida de alguns itens.

Com o objetivo de melhoria dos indicadores e, por conseguinte, da atuação ambiental por parte da empresa, realiza-se a fase denominada de "Decisão", onde inicialmente é realizado um estudo de disponibilidade de capital para investimentos no atendimento dos fatores considerados críticos, neste sentido, realizam-se, também, em alinhamento com as novas exigências da lei 6.404/76 relatada no Capítulo 2, a análise da Demonstração do Fluxo de Caixa da organização.

Ao ser utilizado uma forma de priorização, o objetivo é facilitar para o analista quais fatores devem ser atendidos, além de possibilitar ter uma base de atuação, informada pela análise do caso com a metodologia do próprio sistema. Vale salientar que o método $5 \mathrm{~W} 2 \mathrm{H}$ é conhecido e de livre utilização, servido como uma ferramenta usual na academia e nas empresas.

\section{CONSIDERAÇÕES FINAIS}

Para buscar responder à questão-problema, com a fundamentação teórica, verificaram-se as pesquisas que possibilitassem fundamentar tais alterações metodológicas, sendo que a primeira 
buscou identificar as convergências e divergências do método Sicogea em suas aplicações; o segundo realizou uma pesquisa acerca dos pontos a serem alterados na metodologia do sistema.

A partir dos resultados do que seria possível alterar no método, tendo em vista pontos a serem fortalecidos que se identificou nas pesquisas realizadas, pode-se verificar que um dos quesitos que apresentava problemas é quanto à resposta da lista de verificação no Sicogea original, que são "Sim"; "Não" e "Não se adapta", ou seja, houve casos em que as respostas não seriam totalmente um "Sim", por exemplo. Existia uma necessidade de se pontuar estas respostas. Vale ressaltar que convencionar os grupos-chave e subgrupos foi um dos pontos de prioridade, na intenção de comparabilidade de análises entre estudos da mesma área.

Quanto à fundamentação teórica, acredita-se que se demonstrou eficaz para a continuidade em relação aos demais assuntos tratados, na busca de atender os objetivos propostos e respostas às questões problema. Inicialmente foi abordado o tema Contabilidade Ambiental, que serviu de base para a estrutura do método Sicogea e possíveis alterações realizadas na sua metodologia; entendimentos que se fizeram necessário para compreender o Grupo-chave "Contabilidade e Finanças".

Por ser um ramo da contabilidade geral, a contabilidade ambiental também foi afetada pelas alterações ocorridas na Lei 6.604/76. Assim, em alinhamento com estas novas exigências, sugeriuse a inclusão da análise da DVA e da DFC no sistema estudado.

Partindo-se do exposto por Ávila e Paiva (2006, p. 476), quanto ao Sistema de Gestão Ambiental, constitui-se em "[...]uma estrutura padronizada montada para gerenciar as atividades referentes ao meio ambiente, de forma sistematizada e que possibilite gerar informações". Dessa forma, o Sicogea - Geração 2 está estruturado, possuindo uma metodologia de aplicação, que visa auxiliar na gestão dos fatores ambientais, e possibilita, com base nos dados obtidos, gerar informações aos seus usuários.

A segunda pesquisa verificada realizada por Nunes et al. (2009), buscou verificar a estrutura do Sicogea e propor algumas alterações metodológicas, entre elas: alteração na estrutura da lista de verificação; lista dividida por Grupos-chave e Subgrupos; inclusão de Questões-chave nos itens da lista; forma de respostas de 0 (zero) a 5 (cinco); atribuição de pontos diferentes por questão a critério do analista; inclusão da planilha de ponderação; outra estrutura de indicadores; inclusão de duas fórmulas para identificar os índices de eficiência dos itens; e sugestão de estrutura do 5W2H para as aplicações futuras.

Os resultados obtidos com os estudos identificados; integraram a metodologia do Sicogea Geração 2, que abordou todas as etapas, fases e ações a serem realizadas na aplicação do método. Como resultado, foi proposta a padronização da nomenclatura existente, tendo em vista que, a estrutura metodológica do Sicogea foi composta relacionando denominações vinculadas ao estudo da cadeia produtiva de arroz ecológico.

As principais alterações foram na Etapa 3, denominada "Contabilidade e Controladoria Ambiental", mais especificamente na primeira Fase - Investigação e Mensuração; em sua Ação 1 Sustentabilidade e Estratégia Ambiental, que resultaram em uma nova metodologia de cálculo do grau de sustentabilidade, forma de obter dados com a lista de verificação e indicadores ambientais.

\section{REFERÊNCIAS}

Andrews, R. et al. (2001) Environmental management systems: history, theory, and implementation research. In: National database on environmental management systems. Chapel Hill, NC: University of North Carolina at Chapel Hill.

Ávila, G.J., Paiva, E.L. (set.-dez. 2006) Processos operacionais e resultados de empresas brasileiras após a certificação ambiental ISO14001. Gestão \& Produção, São Carlos, 13(3), 475-487. 
Ávila, L.A. (2001) GAIA - Um método de gerenciamento de aspectos e impactos ambientais. Florianópolis: UFSC, 2001. Tese (Doutorado em Engenharia de Produção) - Universidade Federal de Santa Catarina, Brasil.

Barbieri, J.C. (2006) Gestão ambiental empresarial: conceitos, modelos e instrumentos. São Paulo: Saraiva.

Beuren, I.M. et al.. Como elaborar trabalhos de monografias em contabilidade. 3 ed. In: Beuren, I. M. (org.). Metodologia da pesquisa aplicável às ciências sociais: Raupp e Beuren. São Paulo: Atlas, 2006. (Cap. 3, 80 - 83).

Lei $n^{0}$ 6.404/76. Dispõe sobre as sociedades por ações: compilada com a Lei 11.638/07 e 11.941/09. Recuperado em 15 dezembro de 2009, de: <http://www.planalto.gov.br/ccivil_03/LEIS/L6404compilada.htm>.

Cerqueira, J.P. de., Martins, M.C.(2004) Auditorias de sistemas de gestão: ISO 9001, ISO 14001, OHSAS 18001, ISO/EIC 17025, SA 8000, ISO 19011. Rio de Janeiro: Qualitymark.

Hart, S.L., Milstein, M.B. (Maio-Jul. 2004) Criando valor sustentável. RAE Executivo. 3(2), 65-79.

Marion, J.C., Costa, R.S. da. (Jan./Abr. 2007) A uniformidade na evidenciação das informações ambientais. Revista Contabilidade \& Finanças. FEA-USP, São Paulo. n. 43, 20 - 33.

Nunes, João P. de O. et al.(2009) Contribuições de melhoria para o sistema contábil gerencial ambiental - Sicogea. In: XI Congreso Internacional de Costos y Gestión y XXXII Congreso Argentino de Profesores Universitarios de Costos. Trelew, Chubut e Patagônia, Argentina.

Oliveira, L.M. de., Perez Junior, J.H., Silva, C A. dos S.(2004) Controladoria estratégica. (2 Ed.) São Paulo: Atlas.

Paiva, P.R. de.(2003) Contabilidade ambiental: evidenciação dos gastos ambientais com transparência e focada na preservação. São Paulo: Atlas.

Pfitscher, E. D.(2004) Gestão e sustentabilidade da contabilidade e controladoria ambiental: estudo de caso na cadeia produtiva de arroz ecológico.. 252.f. Tese (Doutorado em Engenharia de Produção)- Curso de Pós-Graduação em Engenharia de Produção, Universidade Federal de Santa Catarina. Florianópolis, Brasil.

Rezende, L.R. de. (out/dez, 2006) Vulnerabilidade dos geradores de resíduos de saúde frente às Resoluções n. 358 Conama e RDC n. 306 Anvisa. O Mundo da Saúde. São Paulo: 30 (4), 588597.

Ribeiro, M. de S. (2005) Contabilidade ambiental. São Paulo: Saraiva.

Soares, E. (2003) Metodologia científica: lógica, epistemologia e normas. São Paulo: Atlas. (p. 1720). 
Tachizawa, T. (2004) Gestão ambiental e responsabilidade social corporativa: estratégias de negócios focadas na realidade brasileira. São Paulo: Atlas.

Turner, I. (2009) Measuring performance: environmental management systems. Sustainability of Activities in Zoos and Aquariums. Londres: 43, 82-90.

Van Bellen, H.M. (2002) Indicadores de sustentabilidade: uma análise comparativa 2002. 235f. Tese (Doutorado em Engenharia de Produção) - Curso de Pós-graduação em Engenharia de Produção, Universidade Federal de Santa Catarina. Florianópolis.

Vargas, A. de B. (2009) Sistema contábil gerencial ambiental: uma análise das convergências $e$ divergências. Trabalho de Conclusão de curso (monografia). Curso Ciências Contábeis, Universidade Federal de Santa Catarina, Florianópolis.

Data do recebimento do artigo: 10/10/2010

Data do aceite de publicação: 10/08/2011 